\title{
Load of Firearm Cases in Male at SMS Medical College, Jaipur
}

\author{
Shanti Lal Pargi', Lovekumar Bhagora², Deepali Pathak ${ }^{3}$, R.K. Punia ${ }^{4}$, Rohit Kumar Meena ${ }^{5}$ \\ ${ }^{1}$ Assistant Professor, Dept. of Forensic Medicine, Ananta Institute of Medical Science \& Research Center, \\ Rajsamand, Udaipur, ${ }^{2}$ Assistant Professor, Dept. of Forensic Medicine, Geetanjali Medical College, Udaipur, \\ ${ }^{3}$ Associate Professor, Dept. of Forensic Medicine, SMS Medical College, Jaipur, ${ }^{4}$ Professor, Dept. of Forensic \\ Medicine, SMS Medical College, Jaipur, ${ }^{5}$ Senior Resident, Dept. of Forensic Medicine, SMS Medical College, \\ Jaipur, Rajasthan
}

\begin{abstract}
Introduction: A Firearm is a thermodynamic machine in which the potential energy of the gun- powder is transformed into the kinetic energy of the projectile.

Aims and Objective: To assess the load and analyze the male cases of firearm injuries.

Material and Methodology: The present prospective study had been conducted in the Department of Forensic Medicine, SMS Medical College \& Hospital, Jaipur, Rajasthan during the period of One \& half year from May 2014 to October 2015. All cases of firearm injuries that were received dead or live at SMS Hospital and its attached Hospitals, Jaipur was included in our study.

Result and Observation: In our study majority of firearm injury case [43 cases (40.78\%)] were observed in the age group of 20-29 years followed by the age group of 30-39 years [28 cases (27.18\%)]. Majority of the incidences of gun-shot injuries were homicidal in nature $(80.58 \%)$ followed by accidental episodes $(14.56 \%)$. Land and property disputes were the most common reason behind firearm injuries in this study (42.72\%) followed by revenge \& robbery $(15.53 \%$ \& $13.59 \%$ respectively);Majority of the incidences occurred during evening in 43 cases $(41.75 \%)$, followed by afternoon 40 cases $(38.83 \%)$. There was presence of firearm entry wound in all victims. Overall,52 cases $(50.49 \%)$ had a single entrance wound, 13 cases $(12.62 \%)$ had two entry wounds, In summer season 43 cases $(41.75 \%)$, spring 24 cases $(23.30 \%)$, winter 20 cases $(19.42 \%)$, autumn 16 cases $(15.53 \%)$, were reported in studied cases. In majority of the cases $(81.55 \%)$, there was no exit wounds while one exit wound was found in 17 cases $(16.51 \%)$.In rest of the two cases, two exit were found in two cases.
\end{abstract}

Conclusion: The results of the present study support the argument that rigorous pursuit of campaign firearms without a license and country made guns may prove useful in reducing the number of firearm injuries in society.

Keyword: Firearm Injury, Male, Prospective study, Jaipur.

\section{Corresponding Author:}

\section{Dr. Lovekumar Bhagora}

Assistant Professor, Dept. of Forensic Medicine, Geetanjali Medical College, Udaipur- 313001, Rajasthan

Contact No.: 9586502020

e-mail: lovebhagora2000@yahoo.com

\section{Introduction}

A Firearm is a thermodynamic machine in which the potential energy of the gun- powder is transformed into the kinetic energy of the projectile ${ }^{1}$.

Firearms and explosives constitute convenient means of destroying human life from considerable distance, providing opportunity to the offender to escape; 
it has been the weapon of choice for gangsters, terrorists, extremists, antisocial and anti-national elements for eliminating their victims. Its use is increasing in recent years because of easy availability due to manufacture of huge amount of arms, ammunition and explosives and free snuggling across the international borders ${ }^{2}$.

Data on firearm injury in a particular geographic area can also give the reflection of its law and order situation. A low value can be described in favour of peace, harmony and security to human life ${ }^{3}$.

There is growing concern about the indiscriminate use of firearms on a large scale, particularly in the last decade. The availability of firearms known as small arms and light weapons (SALW) has been described as a cancer spreading across the developing world ${ }^{4}$.

This study was thus undertaken to assess the load of gun-shot injuries among in Jaipur region and to ascertain the medico-legal and socio-demographic profile of cases presented at SMS Medical College, Jaipur during the study period along with associated deaths in Jaipur region to look for reason behind them; and also to suggest few recommendations which may prove useful in bringing down the toll of firearm injuries in this region.

Aims and Objectives: To assess the load and analyze the cases of firearm injuries and associated deaths reported at the Department of Forensic Medicine, SMS Hospital, Jaipur during the study period (May, 2014 to October, 2015).

To study the load of firearm injuries and associated deaths reported at the Department of Forensic Medicine during the study period .

To study the medico-legal profile of firearm injuries.

To study the socio-demographic profile of victims of firearm injuries.

\section{Material and Methodology}

All the cases of firearm injuries, irrespective of age, gender and socioeconomic status received at the casualty of SMS Hospital, Jaipur, dead or alive, later admitted to various wards of SMS Hospital, Jaipur were included in the study. All cases of firearm injuries that were received dead at SMS Hospital and its attached Hospitals, Jaipur was autopsied at the mortuary of SMS Hospital, Jaipur and included in the study. Also the cases of non fatal firearm injuries admitted to various wards of SMS Hospital and its attached hospitals, Jaipur were included in the study after receiving an informed consent for the same. All the observations were recorded in the pre proposed Performa as detailed above. The results of the present study were further compared to other contemporary studies from various parts of the country.

\section{Observations and Result}

Table 1: Age and Sex Wise Distribution of Firearm Injuries Cases.

\begin{tabular}{|c|c|c|}
\hline Age group (in yrs) & Total no. of cases & Percentage (\%) \\
\hline$<10$ & 01 & 0.97 \\
\hline $10-19$ & 08 & 7.77 \\
\hline $20-29$ & 42 & 40.78 \\
\hline $30-39$ & 28 & 27.18 \\
\hline $40-49$ & 13 & 12.62 \\
\hline $50-59$ & 09 & 8.74 \\
\hline$>60$ & 02 & 1.94 \\
\hline Total & $\mathbf{1 0 3}$ & $\mathbf{1 0 0}$ \\
\hline
\end{tabular}

Out of 103 cases, majority of the cases were in the age group of 20-49 years [(42 cases $(80.58 \%)]$ which is productive age group of society. Among these, maximum cases were in the age group of 20-29 years which comprised about $40.78 \%$ of total cases. The other age groups affected in descending order were the $4^{\text {th }}, 5^{\text {th }}$, $6^{\text {th }}$ and $2^{\text {nd }}$ decades. The least affected age groups with only 2 cases and 1 case below 10 years and above 60 years respectively.

Table 2: Manner Wise Distribution of Firearm Injuries Cases.

\begin{tabular}{|l|c|c|}
\hline Manner & $\begin{array}{c}\text { Total no. of } \\
\text { cases }\end{array}$ & Percentage (\%) \\
\hline No. of Homicidal case & 83 & 80.58 \\
\hline No. of Accidental case & 15 & 14.56 \\
\hline Unknown cases & 3 & 2.91 \\
\hline No. of Suicidal case & 2 & 1.94 \\
\hline Total no. of cases & $\mathbf{1 0 3}$ & $\mathbf{1 0 0}$ \\
\hline
\end{tabular}

Homicides $(80.58 \%)$ were the most common manner of firearm injuries in the present study followed by 15 cases (14.56\%) accidental and 02 cases $(1.94 \%)$ suicidal firearm injuries. The manner remained undetermined in 03 cases $(2.91 \%)$. 
Table 3: Motive Behind the Incidence Wise Distribution of Firearm Injuries Cases.

\begin{tabular}{|l|c|c|}
\hline Motive behind incidence & $\begin{array}{c}\text { Total no. of } \\
\text { cases }\end{array}$ & $\begin{array}{c}\text { Percentage } \\
\mathbf{( \% )}\end{array}$ \\
\hline Property disputes & 44 & 42.72 \\
\hline Revenge & 16 & 15.53 \\
\hline Robbery & 14 & 13.59 \\
\hline Unknown & 09 & 8.74 \\
\hline Accidental (no motive) & 09 & 8.74 \\
\hline Group Quarrel & 05 & 4.85 \\
\hline Love Affair & 03 & 2.91 \\
\hline Defence & 03 & 2.91 \\
\hline Grand Total & $\mathbf{1 0 3}$ & $\mathbf{1 0 0}$ \\
\hline
\end{tabular}

Land and property disputes were the most common reason behind firearm injuries in this study (42.72\%) followed by revenge \& robbery $(15.53 \%$ \& $13.59 \%$ respectively); group quarrel accounted for another 5 cases $(4.85 \%)$ and there were 03 cases each $(2.91 \%)$ for defense and love matters/sexual jealousy. In 9 cases $(8.74 \%)$, the motive remained undetermined.

Table 4: Time of Incidence Wise Distribution of Firearm Injuries Cases.

\begin{tabular}{|l|c|c|}
\hline Day of Incidence & Total no. of cases & Percentage (\%) \\
\hline Evening & 43 & 41.75 \\
\hline Afternoon & 40 & 38.83 \\
\hline Morning & 9 & 8.74 \\
\hline Night & 10 & 9.71 \\
\hline Unknown & 01 & 0.97 \\
\hline Total & $\mathbf{1 0 3}$ & $\mathbf{1 0 0}$ \\
\hline
\end{tabular}

Majority of the incidences occurred during evening in 43 cases $(41.75 \%)$, followed by afternoon 40 cases (38.83\%), night 10 cases $(9.71 \%) \&$ morning 9 cases $(8.74 \%)$ The time of incidence remained undetermined in a single case $(0.97 \%)$.

Table 5: Season of Incidence Wise Distribution of Firearm Injuries Cases.

\begin{tabular}{|l|c|c|}
\hline Season of incidence & $\begin{array}{c}\text { Total no. of } \\
\text { cases }\end{array}$ & Percentage (\%) \\
\hline Summer & 43 & 41.75 \\
\hline Spring & 24 & 23.30 \\
\hline Winter & 20 & 19.42 \\
\hline Autumn & 16 & 15.53 \\
\hline Total & $\mathbf{1 0 3}$ & $\mathbf{1 0 0}$ \\
\hline
\end{tabular}

In summer season 43 cases ( $41.75 \%)$, spring 24 cases (23.30\%), winter 20 cases(19.42\%), autumn 16cases $(15.53 \%)$, were reported in studied cases. Maximum were in summer and least in autumn.

Table 6: Number of Exit Wounds in Gun-Shot Injuries Wise Distribution of Firearm Injuries Cases.

\begin{tabular}{|l|c|c|}
\hline Number of Exit wounds & $\begin{array}{c}\text { Total no. of } \\
\text { cases }\end{array}$ & $\begin{array}{c}\text { Percentage } \\
(\mathbf{\%})\end{array}$ \\
\hline None & 84 & 81.55 \\
\hline One & 17 & 16.51 \\
\hline Two & 02 & 1.94 \\
\hline Total & $\mathbf{1 0 3}$ & $\mathbf{1 0 0}$ \\
\hline
\end{tabular}

In majority of the cases [84 cases (81.55\%)], there were no exit wounds while one exit wound was found in 17 cases $(16.51 \%)$.In rest of the two cases, two exit wound were found in two cases.

\section{Discussion}

Maximum numbers of cases were from 20-39 years of age $(67.96 \%)$ with peak incidence in 20-29 years $(40.78 \%)$ which are the productive and active members of the society. The observations of the present study were similar to those of Patowary AJ et $\mathbf{a l}^{4}$, Sachan $\mathbf{R}$ et $\mathbf{a l}^{\mathbf{5}}$, Kumar $\mathbf{K}$ et $\mathbf{a l}^{\mathbf{6}}$ (peak incidence between 21-40 years of age in all). However, the results of the present study are variable from those of Kumari $\mathbf{S}$ et $\mathbf{a l}^{7}$ who reported maximum number of cases in 11-20 years followed by 21-30 years. The probable reason for this variation is the minor cultural and periodical differences as most other studies from the same state also report the highest incidences of such cases between 21-40 years.

Homicides [83 cases $(80.58 \%)]$ were the most common manner of firearm injuries in the present study followed by 15 cases $(14.56 \%)$ accidental and 02 cases (1.94\%) suicidal firearm injuries. The manner remained undetermined in 03 cases $(2.91 \%)$. Homicidal intent was predominant in most other studies Sachan $\mathbf{R}$ et $\mathbf{a l}^{\mathbf{5}}$, Kumar $\mathrm{K}$ et $\mathbf{a l}^{6}$ and Kumari $\mathrm{S}$ et $\mathbf{a l}^{7}$. Other studies have considered either only homicidal Patowary AJ et $\mathbf{a l}^{4}$ or suicidal firearm injuries. The preponderance of homicide in gun-shot injuries is explainable as these deadly weapons are generally used in planned manner or more so impulsively in a planned assault. It is not very easy to procure such weapons and not that very easy to carry it due to legal restraints, so, they are not 
the weapon of choice in fights and assaults. They are mostly used in planned episodes of homicidal or suicidal injuries. Accidental injuries with firearms are also not uncommon as users are prone to such episodes while cleaning, maintenance or erratic handling of loaded guns. Accidental injuries were seen in this study in $16.52 \%$ cases but these results are quite high as compared to studies of Kumar $\mathrm{K}$ et $\mathbf{a l}^{6}$ and Kumari $\mathrm{S}$ et $\mathrm{al}^{7}$.

Land and property disputes were the most common reason behind firearm injuries in this study [44 cases (42.72\%)]followed by revenge 16 cases(15.53\%) \& robbery 14 cases (13.59\%); group quarrel accounted for another 5 cases $(4.85 \%)$ and there were 03 cases each (2.91\%) for defense and love matters/sexual jealousy. In 9 cases $(8.74 \%)$, the motive remained undetermined. As per Kumar $\mathbf{K}$ et $\mathbf{a l}^{\mathbf{6}}$ the motive remained undetermined in a single case of accidental firing (1.73\%). This difference is attributable to the variation in the proportion of accidental incidences in the two studies. There were 10 cases of purely accidental gun-shot injuries where motive was lacking. According to Patowary AJ et $\mathbf{a l}^{\mathbf{5}}$ - Most cases were due to militant activities, encounters, riots, robberies or family quarrel. This variation from our study is due to the regional variations in the areas of study as Guwahati and Imphal are militant activity prone areas. The results of the present study are quite similar to those of Sachan $\mathbf{R}$ et $\mathbf{a l}^{\mathbf{5}}$. But, in slight variation with Kumar $\mathbf{K}$ et $\mathbf{a l}^{\mathbf{6}}$ where maximum homicides occurred for personal enmity. The motives behind the homicidal attack with firearm weapons were well represented in different cases with property land disputes majorly responsible followed by personal enmity and robbery.

Most of the events of firearm injuries occurred during evening hours $(41.75 \%)$ followed by afternoon $(38.83 \%)$. These are the hours of work and business, thus prone to activity during which the untoward event took place. $8.74 \%$ incidences took place in morning hours. Thus, it was observed that in $47.57 \%$ cases, the incidence took place in broad daylight and $52.43 \%$ cases occurred after sunset; as also reported by Kumar K et $\mathbf{a l}^{6}$. The late night hours witnessed the least numbers of gun-shot injuries (8.7\%) in the present study which is in contrast to the findings of Kumari $S$ et al. The suicides (two cases) were committed in morning and evening each.

None of the season was poorly represented by episodes of firearm injuries and deaths. However, summer season was most flooded with events of firearm injuries in the present study (41.75\%) followed by spring $(23.30 \%)$ and winter $(19.42 \%)$. This is quite explainable as maximum events in this study took place for land disputes in villages. Summer season is a comparatively relaxing one for those engaged in Agriculture as the main crop of this region is through by the end of spring. After the harvest of the crop, the disputes probably come to surface owing to distribution of revenue generated.

Exit wounds were present in only 84 cases (18.26\%) i.e. in majority of the victims, firearm exit wounds were not present. These are quite less in number due to the predominance of distant fires in this study. In the present study, a single exit wound was found in 17 cases $(16.51 \%)$ and in 2 cases $(1.74 \%)$ there were two exit wounds. These results are quite low in comparison to those of Kumar $\mathbf{R}$ et $\mathbf{a l}^{\mathbf{2}}$ and, Kumari $\mathbf{S}$ et $\mathbf{a l}^{7}$ who reported presence of exit wounds in $61.36 \% \& 60 \%$ victims respectively.

\section{Conclusion}

This study indicated that the most common victims of firearm injuries were young males of bread earning age followed by youth which raises concern towards this issue. Certain changes may minimize mortality and disability due to firearm injuries, also reducing the costs to the community. As a result of the invention of more advanced firearms and availability at the global level, death rates due to firearm injuries have increased recently. There is a powerful correlation between acquisition of a firearm and its use in murders, suicides and unintentional deaths. So, there is a need to decrease the number of firearms used and sold in India.

The results of the present study support the argument that rigorous pursuit of campaign firearms without a license and country made guns may prove useful in reducing the number of firearm injuries in society. Educational efforts and individual, community and societal approaches are needed to alleviate firearm related injuries.

\section{Source of Funding: Self}

\section{Conflict of Interest: Nil}

\section{Acknowledgement: Nil}

Ethical Clearance: It is taken from Ethical committee of SMS Medical College, Jaipur before starting of study. 


\section{Reference}

1. Aggrawal Anil, Forensic Medicine and Toxicology. APC. Edition: 2017, Page: 180.

2. Kumar R et al. Study of wounds in victims of homicide by firearms and explosives. Journal of Evolution of Medical and Dental Sciences 2013; Vol. 2(44), November 04; Page: 8517-8539.

3. Rahim M, Das TC. Mortuary profile for unnatural deaths at Forensic Medicine department of Dhaka Medical College. Bangladesh Medical J. 2009;38(2):44-7.

4. Patowary A. Study of pattern of injuries in homicidal firearm injury cases. JIAFM 2005; 27(2):92-95
5. Sachan R, Kumar AA, Verma AA. Frequency of fire arm injuries, death and related factor in Kanpur India. International Journal of Medical Toxicology and Forensic Medicine. 2013; 3(3): 88-95

6. Kumari S, Rajput AS, Agarwal A, Arif A, Chaturvedi RK. Medico-legal Aspects of Firearm Injury Cases in Agra Region. J Indian Acad Forensic Med. 2014; 36(4):387-90.

7. Kumar K, Mohanty $\mathrm{S}$ et al. Factors Influencing the Pattern Of Firearm Injuries In Ganjam - A Ten Years Retrospective Study 2014. Vol-1(32) 2014:1-7] 